\title{
Size-Dependent Composition of Semiconductor Nanoparticles in Glass*
}

P. D. Persans, L. B. Lurio ${ }^{+}$, M. Frederick, M. Stukowski, and T. M. Hayes

Physics Department, Rensselaer Polytechnic Institute, Troy, NY, USA

\begin{abstract}
Precipitation of semiconductor particles in glass produces composite materials that are optically useful and mechanically, thermally, and chemically robust. Applications include optical absorption long pass filters and nonlinear saturable absorbers. Control of particle composition is essential to control of optical properties. We demonstrate how Raman scattering, optical absorption spectroscopy, and x-ray absorption spectroscopy can be combined to determine composition, size, and strain in $\mathrm{Zn}_{\mathrm{x}} \mathrm{Cd}_{1-\mathrm{x}} \mathrm{S}$ semiconductor nanoparticles grown in glass. We develop a thermophysical model relating average particle size and $\mathrm{Zn} / \mathrm{Cd}$ ratio in nanoparticle precipitates.

* Supported by DOE DE-FG02-97ER45662.
\end{abstract}

Contact: P. D. Persans, Physics Department, Rensselaer Polytechnic Institute, Troy, NY 12180 persap@rpi.edu

518-276-2934

+ Current address: Northern Illinois University, Department of Physics, IL, USA 


\section{Introduction}

$\mathrm{Zn}_{\mathrm{x}} \mathrm{Cd}_{1-\mathrm{x}} \mathrm{S}_{\mathrm{y}} \mathrm{Se}_{1-\mathrm{y}}$ nanoparticles precipitated in glass have long been the basis for visible optical filter technology [1]. The absorption edge of such filter glasses can be controllably altered from $400 \mathrm{~nm}$ to $700 \mathrm{~nm}$ by varying particle composition from $\mathrm{ZnS}$ rich to CdSe-rich. The seminal work of Ekimov and collaborators demonstrated that the optical properties of such glasses could also be profoundly altered through quantum confinement and other size effects $[2,3]$. Simultaneous control of particle size and composition will extend the range of applications of nanoparticle/glass systems.

Nanoparticles are typically grown from a supersaturated solution of reactants in the glass. During particle growth, and certainly during ripening of the particle size distribution, the supply of reactants must be depleted significantly. In a multicomponent system, the change in reactant composition must lead to a change in particle compositon. In this paper we address the relationship between particle size, reactant concentration, and particle composition for the model system of $\mathrm{Zn}_{\mathrm{x}} \mathrm{Cd}_{1-\mathrm{x}} \mathrm{S}$ particles in borosilicate glass. We note that variation of composition with time in similar glasses was first reported by Borelli et al. in 1987 [4].

\section{Theoretical relationship between glass composition, particle size, and particle composition}

Our base glass consists of $\mathrm{SiO}_{2}: \mathrm{B}_{2} \mathrm{O}_{3}: \mathrm{Na}_{2} \mathrm{O}: \mathrm{CaO}: \mathrm{K}_{2} \mathrm{O}: \mathrm{ZnO}$ in the approximate ratios 73:13:6:4.5:2:0.4, as determined by x-ray fluorescence, x-ray absorption spectroscopy, and electron microprobe [5]. It also contains $1.1 \times 10^{19} \mathrm{Cd} / \mathrm{cm}^{3}(0.1 \mathrm{wt} . \%)$ and 
approximately four times that amount of S. In the discussion that follows, we assume that $\mathrm{Cd}$ is the limiting reactant in the formation of $\mathrm{CdS}$ nanoparticles.

From analysis of $\mathrm{x}$-ray absorption fine structure at the $\mathrm{Cd}$ k-edge, we have shown that $\mathrm{Cd}$ is found primarily in only two environments, dissolved in the glass host with $\mathrm{O}$ neighbors or concentrated in CdS clusters or particles $[5,6]$. This observation, coupled with the assumption that the average particle radius and reactant concentrations change slowly compared with the time for a reactant moiety to diffuse between or within particles, leads to simple relationships between particle size and Cd concentration [7-11].

The minimum stable particle size $R_{\mathrm{C}}$ during homogeneous nucleation and ripening is determined by the balance between volume energy and surface tension: $R_{\mathrm{C}}=2 \gamma / \Delta G_{\mathrm{V}}$ where $\Delta G_{\mathrm{V}}=-(k \mathrm{~T} / V) \ln \left(C_{\mathrm{Cd}} / C_{\mathrm{e}}\right)$ is the free energy change between "dissolved" $\mathrm{Cd}$ and solid CdS (per unit CdS crystal volume). $\gamma$ is the effective surface energy per unit area. We have previously estimated $\gamma$ to be $\sim 0.03 \mathrm{Nm}^{-1}$ from nucleation studies [9]. $C_{\mathrm{Cd}}$ is the radius-dependent concentration of the dissolved $\mathrm{Cd}$ in the host glass and $C_{\mathrm{e}}$ is the equilibrium concentration of $\mathrm{Cd}$ at the heat treatment temperature. Solving for $C_{\mathrm{Cd}}$ yields,

$$
C_{\mathrm{Cd}}=C_{\mathrm{e}} \exp \left(A / k \mathrm{~T} R_{\mathrm{C}}\right)
$$

where $A=2 \gamma V$ is expected to be nearly temperature independent. For long growth times or large particle radii, the measured $\mathrm{Cd}$ concentration in the host approaches the equilibrium concentration.

We can write an equilibrium relation for the ratio of $\mathrm{Zn}$ to $\mathrm{Cd}$ in particles:

$$
\frac{x}{1-x}=\frac{C_{Z n}(\text { particle })}{C_{C d}(\text { particle })}=K \frac{C_{Z n}(\text { host })}{C_{C d}(\text { host })}
$$


where $K$ is the ratio of equilibrium constants for $\mathrm{Zn}$ and $\mathrm{Cd}$ incorporation respectively. Since there is several times more $\mathrm{Zn}$ than $\mathrm{S}$ dissolved in the glass and it is unlikely to deplete, we therefore assume that $C_{\mathrm{Zn}}$ (host) is constant and the combination of equations

1 and 2 gives: $\frac{x}{1-x}=K \frac{C_{Z n}(\text { host })}{C_{e}} \exp \left(-\frac{A}{k T R_{C}}\right)$. For small $x$, we have

$$
x \approx x_{0} \exp \left(-\frac{A}{k T R_{C}}\right)
$$

where

$$
x_{0}=K \frac{C_{Z n}(h o s t)}{C_{e}}
$$

is the $R_{\mathrm{C}}=0$ (equilibrium ) intercept for each temperature. We expect $\mathrm{x}_{0}$ to be activated because both $C_{\mathrm{e}}$ and $K$ will be activated. Thus, we find that the ratio of $\mathrm{Zn}$ to $\mathrm{Cd}$ within particles depends on the critical radius, which evolves with time as $\mathrm{Cd}$ is depleted from the glass.

During ripening, the particle size distribution becomes non-Gaussian as smaller particles become unstable and larger particles grow. For low particle density, the Lifshitz-Slyozov model describes the distribution well [7]. The peak in the Lifshitz-Slyozov distribution falls at $\sim 1.2 R_{\mathrm{C}}$, simply scaling the constant $A$ in eq. 3 down by a factor of 1.2 .

\section{Experimental Details and Analysis}

We combine the analysis of x-ray absorption fine structure (XAFS), optical absorption spectra, and resonant Raman spectra to deduce the size and composition of particles [11]. A summary of this approach follows. The lowest energy optical transition and the LO phonon Raman energy depend, in different ways, on the particle composition, size, and 
strain. A description of optical, Raman, and XAFS measurement can be found elsewhere [11]. We have previously shown using XAFS that strain in this system is small [12], so we neglect it here.

Quantum confinement produces a shift in the band edge with size. For particles of radius $2<\mathrm{R}<6 \mathrm{~nm}$, the empirical relationship

$$
E_{G}(R)-E_{B U L K}=1.7 / R^{2}
$$

yields good agreement with the literature [13]. In our measurement of the shift, we determine the most frequent particle size by determining the energy of the peak or second inflection point in the optical absorption spectrum [9]. Substitutional incorporation of $\mathrm{Zn}$ for $\mathrm{Cd}$ in $\mathrm{CdS}$ also produces an increase in the band gap that is empirically described by [14]

$$
E_{B U L K}(x)=2.45+0.705 x+0.603 x^{2} .
$$

Incorporation of $\mathrm{Zn}$ for $\mathrm{Cd}$ also causes a shift in the $\mathrm{LO}$ phonon Raman peak that is empirically described by

$$
\omega(x)=303+91.4 x-44.2 x^{2}
$$

for $\mathrm{x}<0.2$ [14]. For particles in this size range, the shift in the LO phonon Raman peak due to size alone is smaller than $1 \mathrm{~cm}^{-1}[11]$.

For $x<0.2$ and $2 \mathrm{~nm}<R<6 \mathrm{~nm}$, size and $\mathrm{Zn}$ incorporation shifts can be added linearly and the simultaneous solution of equations 4-6 yields $R$ and $x$. For a given set of measurements, it is simplest to start with the Raman shift to determine $x$ (eq. 6). The shift in the bulk band gap due to composition (eq. 5) can then be determined. Finally, the size is deduced using eq. 4. 
The Raman shift can be determined experimentally to $\pm 0.5 \mathrm{~cm}^{-1}$, yielding uncertainty in $x$ of \pm 0.0005 . This in turn yields an uncertainty in $\mathrm{E}_{\mathrm{BULK}}$ of $\pm 5 \mathrm{meV}$, which is small compared with the measurement uncertainty of $\pm 20 \mathrm{meV}$ in the shift of the bandgap. Given the composition-dependent bulk bandgap we can easily deduce the size shift. The combination of uncertainties from Raman peak position and band edge shift leads to an uncertainty in $R$ of $\pm 0.4 \mathrm{~nm}$ for $R=6 \mathrm{~nm}$ and of $\pm 0.1 \mathrm{~nm}$ for $R=2 \mathrm{~nm}$.

\section{Results and Discussion}

In Fig. 1 we plot the $\mathrm{Zn}$ fraction $x$ against inverse particle radius for three representative temperatures. The data are clearly consistent with the radius-dependent aspect of equation 3, $x=x_{0} \exp \left(A / k \mathrm{~T} R_{\mathrm{C}}\right)$. Straight-line fits of $\ln (x)$ against $1 / R_{\mathrm{C}}$ yield $A$ and the intercept $x_{0}$. We find that $A$ is indeed nearly independent of temperature. The $\log$ intercept of $x_{0}$ is plotted against 1/T in Fig. 2. We observe that it is activated, $x_{0}=x_{00} \exp \left(E_{\mathrm{X}} / k \mathrm{~T}\right)$, with $x_{00}=1.8 \times 10^{-3}$ and $E_{\mathrm{x}}=0.36 \mathrm{eV}$.

The activation energy of $x_{0}$ arises from the ratio $K / C_{\mathrm{e}}$. It is possible to independently determine $C_{\mathrm{e}}$ directly by measurement. In Fig. 4 we plot the equilibrium concentration of Cd dissolved in the oxide phase as a function of temperature. Points labeled with squares were determined directly from XAFS analysis of Cd neighbors. Points labeled with circles (at lower temperatures) were determined by extrapolating the time-dependent Cd$\mathrm{O}$ bond density [10]. The equilibrium concentration is activated, $C_{\mathrm{e}}=C_{0} \exp \left(-E_{\mathrm{e}} / k \mathrm{~T}\right)$, with $C_{0}=1.8 \times 10^{23} \mathrm{~cm}^{-3}$ and $E_{\mathrm{e}}=0.87 \mathrm{eV}$. Above $950^{\circ} \mathrm{C}$ the CdS phase is fully dissolved into the glass. 
With knowledge of $x_{0}, C_{\mathrm{e}}$, and $C_{\mathrm{Zn}}$, from eq. $3 \mathrm{~b}$ we find $K=K_{0} \exp \left(E_{\mathrm{K}} / k \mathrm{~T}\right)$ with $K_{0}=6$ and $E_{\mathrm{K}}=-0.5 \mathrm{eV}$.

\section{Summary}

We have formulated a quantitative model relating the composition and size of $\mathrm{Zn}_{\mathrm{x}} \mathrm{Cd}_{1-\mathrm{x}} \mathrm{S}$ nanoparticles in glass to processing history and reactant concentrations in the host glass. XAFS measurements of Cd atomic environments, Raman measurements of particle composition, and optical absorption measurements are combined to deduce all important thermochemical parameters for a borosilicate host glass that contains $1.1 \times 10^{19} \mathrm{Cd} \mathrm{cm}^{-3}$ with excess Zn and S.

The following are some useful relationships that derive from the measurements and model.

1. The equilibrium concentration of $\mathrm{Zn}$ in particles decreases in an activated manner with increased $\mathrm{T}\left(E_{\mathrm{x}}=0.36 \mathrm{eV}\right)$. This is primarily driven by the increase in equilibrium dissolved Cd concentration with increased $\mathrm{T}\left(E_{\mathrm{e}}=0.87 \mathrm{eV}\right)$.

2. For a given temperature, the $\mathrm{Cd}$ concentration in the glass decreases exponentially as particle size increases. This is a direct consequence of ripening of the particle size distribution.

3. For a given size, the $\mathrm{Zn}$ concentration in particles decreases in an activated manner with increased $\mathrm{T}$. The activation energy depends on size.

\section{Acknowledgements}

We gratefully acknowledge funding by the Department of Energy (DOE) Office of Basic Energy Sciences grant DE-FG0297ER455662. The XAS measurements were made at 
SSRL, which is funded by the DOE Office of Basic Energy Sciences and the NIH Biotechnology Resource Program. Doped experimental glass samples were supplied by Schott Glass Inc. 


\section{Figure Captions}

Figure 1 - Zn fraction $x$ plotted against particle radius for particles prepared at three representative temperatures; $650^{\circ} \mathrm{C}(\mathrm{X}), 675^{\circ} \mathrm{C}(*)$, and $725^{\circ} \mathrm{C}(\Delta)$. Solid lines are linear fits of $\log (x)$ against $1 / R$.

Figure $2-\log _{10}\left(x_{0}\right)$, determined from the $\mathrm{R}=\infty$ intercept to linear fits shown in Fig. 1 , plotted against $1 / T$. The solid line is a linear fit as described in the text.

Figure 3 - Equilibrium concentration of $\mathrm{Cd}$ in borosilicate glass doped with $\mathrm{Cd}, \mathrm{Zn}$, and $\mathrm{S}$ as discussed in the text. Squares are deduced directly from Cd-edge XAFS measurements on equilibrated and quenched samples and circles are deduced from sizedependent concentrations measured by XAFS [10]. 


\section{References}

1. W.A. Weyl, Coloured Glasses. 1959, London: Dawsons of Pall Mall.

2. A.I. Ekimov and A.A. Onuschchenko, JETP Letters, 1981. 34: p. 345.

3. A.I. Ekimov and A.A. Onushchenko, JEPT Letters, 1984. 40(8): p. 1136-1139.

4. N.F. Borrelli, D. Hall, H. Holland, and D. Smith, J. Appl. Phys., 1987. 61: p. 5399.

5. P.D. Persans, L.B. Lurio, J. Pant, H. Yukselici, G. Lian, and T.M. Hayes, J. Appl. Phys., 2000. 87: p. 3850-7.

6. T.M. Hayes, L.B. Lurio, R.J. Olsson, J. Pant, H. Yukselici, and P. Persans, Physica B, 1995. 208/209: p. 585.

7. I.M. Lifshitz and V.V. Slyozov, J. Phys. Chem. Solids, 1961. 19: p. 35.

8. S.A. Gurevich, A.I. Ekimov, I.A. Kudryavtsev, O.G. Lyublinskaya, A.V. Osinskii, A.S. Usikov, and N.N. Faleev, Semiconductors, 1994. 28: p. 486.

9. H. Yukselici, P.D. Persans, and T. Hayes, Phys. Rev. B, 1995. 52: p. 11763.

10. T.M. Hayes, L.B. Lurio, and P.D. Persans, J. Phys. Cond. Matt., 2001. 13: p. 42531.

11. P.D. Persans, L.B. Lurio, J. Pant, G.D. Lian, and T.M. Hayes, Physical Review B, 2001. 63: p. 115320/1-8.

12. T.M. Hayes, L.B. Lurio, J. Pant, and P.D. Persans, Phys. Rev. B, 2001. 63: p. $155417 / 1-4$

13. P.D. Persans and K.L. Stokes, in Handbook of Nanophase Materials, A. Goldstein, Editor. 1996, Marcel Dekker: New York. 
14. O. Madelung, ed. Landolt-Bornstein, Numerical Data and Functional Relationships in Science and Technology. Vol. III-17b. 1982, Springer-Verlag: Berlin. 


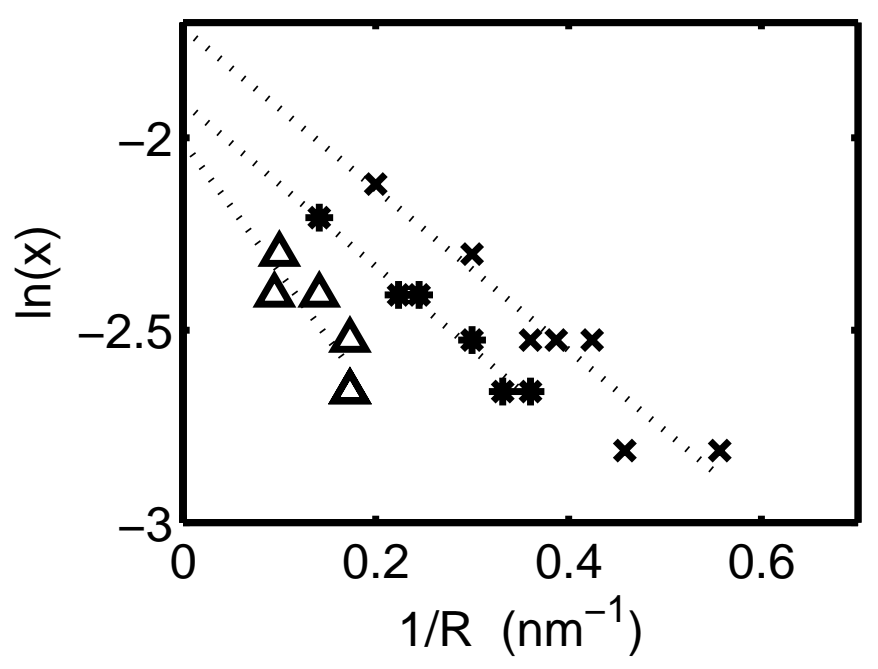

Fig. 1

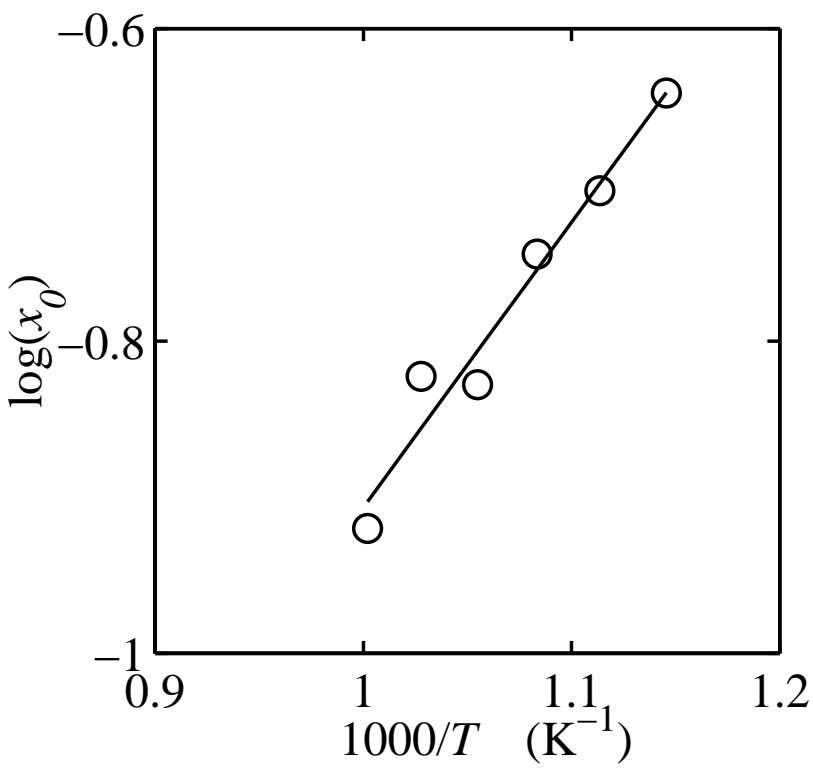

Fig. 2 


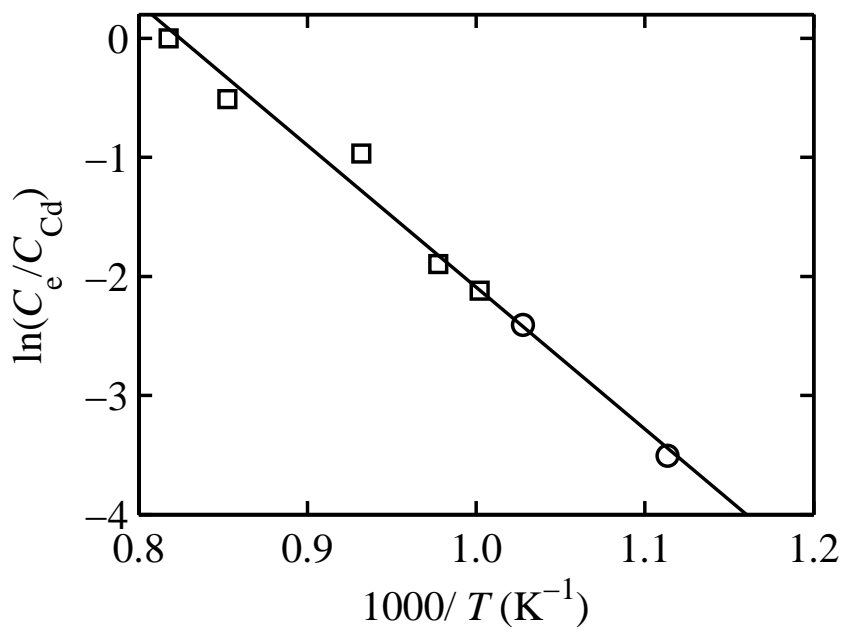

Fig. 3 